\title{
The October 1995 ZCAL Moving Experiment: Output Signals and Position Finding
}

\author{
J. B. Cumming, D. Beavis, Y.Y. Chu, and L.P. Remsberg \\ Brookhaven National Laboratory, Upton, New York 11973, USA
}

(Received 19 July 1996)

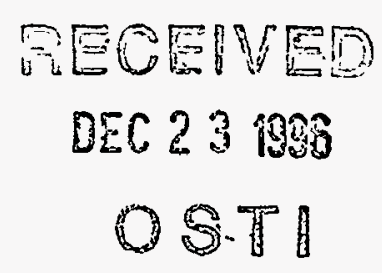

PECEMEOE

OEC 231908

O S. $\mathrm{TH}$

The response of ZCAL, the E866 Downstream Calorimeter, to changes in gold beam position was examined during the Oct 1995 running period. Motion in the $\mathrm{x}$ direction was achieved by physically moving ZCAI: in the y direction by pitching the beam. These new results for gold incident on on a heavily radiation-damaged ZCAL differ substantially from previous data for silicon impinging on a relatively undamaged calorimeter.

\section{INTRODUCTION}

The Zero-degree CALorimeter, ZCAL, of the E802/E859/E866 series of experiments is intended to measure the energy remaining in projectile fragments after a heavy ion collision and, hence, provide an estimate of the impact parameter of the interaction. Figure 1 gives some general information on the calorimeter. Its $1.8-\mathrm{m}$ effective length is divided into two sections, $\mathrm{H} 1$ and $\mathrm{H} 2$ as seen by the beam. The basic stacking unit is composed of a $1-\mathrm{cm}$ iron plate followed by a $0.3-\mathrm{cm}$ scintillator sheet sandwiched between two $\mathrm{TiO}_{2}$ coated Mylar sheets. There are 32 stacking units in 
$\mathrm{H1}, 108$ in H2. Eight light signals from each section are transmitted via wave-length shifter plates(WLSs) to photomultipliers at the rear of ZCAL. The sixteen PMT signals are denoted $H_{1}(1), \ldots$, and $H_{1}(8)$ and $H_{2}(1), \ldots$, and $H_{2}(8)$. Their orientation with respect to the standard coordinate system is shown in the figure.

The response of ZCAL has been studied extensively for a variety of incident beam particles or individual projectile fragments extending from ${ }^{1} \mathrm{H}$ to ${ }^{28} \mathrm{Si}$. For these light ions, ZCAL's output is proportional to the number of incident nucleons at fixed velocity, and its resolution can be optimized by weighting the $\mathrm{H} 1$ and $\mathrm{H} 2$ signals in the ratio 57/43 [1]. An algorithm for calculating the $(x, y)$ coordinates of the centroid of a projectile fragment shower from the basic ZCAL signals has been developed [2] and applied to examine azimuthal asymmetries of emitted particle ratios in intermediate impact-parameter collisions [3]. These measurements were performed with ZCAL containing its original load of scintillator and at a time when the total integrated exposure to ${ }^{16} \mathrm{O}$ and ${ }^{28} \mathrm{Si}$ ions was small.

The situation changed with implementation of the E859 level 2 trigger. As beam intensities were raised to take advantage of the selective data acquisition, effects of radiation damage on ZCAL became apparent: output signals fell and resolution worsened. Partial compensation was achieved by increasing gains, but the scintillator was replaced with fresh material during the summer of 1992 in preparation for the gold beam. Observed response of ZCAL to Au raised a number of questions. Correlations . between the $\mathrm{H} 1$ and $\mathrm{H} 2$ signals which had been used to optimize performance for the lighter ions appeared to be absent for ${ }^{197} \mathrm{Au}$, and the resolution for gold was several times poorer than anticipated by extrapolation from the light ion results. Possible nonlinear response to the highly charged projectile as well as the rapid buildup of radiation damage in $\mathrm{ZCAL}$ are additional problems in interpreting recent $\mathrm{E} 866$ results [4]. The present Memo reports analyses experiments performed during the Oct 1995 


\section{DISCLAIMER}

This report was prepared as an account of work sponsored by an agency of the United States Government. Neither the United States Government nor any agency thereof, nor any of their employees, make any warranty, express or implied, or assumes any legal liability or responsibility for the accuracy, completeness, or usefulness of any information, apparatus, product, or process disclosed, or represents that its use would not infringe privately owned rights. Reference herein to any specific commercial product, process, or service by trade name, trademark, manufacturer, or otherwise does not necessarily "constitute or imply its endorsement, recommendation, or favoring by the United States Government or any agency thereof. The views and opinions of authors expressed herein do not necessarily state or reflect those of the United States Government or any agency thereof. 


\section{DISCLAIMER}

Portions of this document may be illegible in electronic image products. Images are produced from the best available original document. 
running period which shed some light on, and raise further questions concerning ZCAL's response to the ${ }^{197} \mathrm{Au}$ beam.

\section{EXPERIMENTAL PROCEDURES AND RESULTS}

\section{A. General}

Runs 17192-17230 dedicated to studying ZCAL occurred in the midst of the 2K-p bar data acquisition period. After initial setup of beam conditions, ZCAL was lowered to place its wheels on the floor. The beam was pitched down using the BP376 dipole to approximately recenter it on the lowered ZCAL $\mathrm{x}$ axis and the calorimeter was rolled east in several steps to provide data at $x$ values out to $+20 \mathrm{~cm}$. At each stop the BP471 dipole was used to map the y response for deflections up to $9 \mathrm{~cm}$ above the $\mathrm{x}$ axis. Mean beam position in each run relative to the nominal beam center line was determined from the HODO array. Each point in the present analysis is based on $\sim 10 \mathrm{k}$ clean BEAM events obtained under empty target conditions.

\section{B. ZCAL Energy Signals and Resolution}

Gain calibrations for ZCAL in these measurements are such that a ${ }^{197} \mathrm{Au}$ beam centered on the HODO array, i.e., on $\mathrm{x}$ and $\mathrm{y}$ slats numbered 20 , would give balanced outputs from the individual PMTs; apparent energies deposited in the two sections of ZCAL, $H_{1}=H_{1}(1)+\cdots+H_{1}(8)$ and $H_{2}=H_{2}(1)+\cdots+H_{2}(8)$, respectively, in the ratio $H_{1} / H_{2}=57 / 43$; and a total energy signal $E_{Z C A L}$ of $2088 \mathrm{GeV}$.

The dependence of $H_{1}, H_{2}$, and their sum, $E_{Z C A L}$, on beam position relative to the ZCAL center is shown in Fig. 2(a). Data for the traverse along the $\mathrm{x}$ axis(filled points) and for the one along y (open points) at $x \sim 0$ fall on the same curve, as expected from symmetry of the calorimeter. Comparable data for incident ${ }^{28} \mathrm{Si}$ ions are shown in Fig. 2(b) for comparison. Note that the ordinate ranges in the lower 
sections of Fig. 2(a) and (b) span one decade for each projectile. The much stronger dependence on position in the case of ${ }^{197} \mathrm{Au}$ is striking: $E_{Z C A L}$ increases by a factor of three in moving out to $20 \mathrm{~cm}$. Radiation damage from the incident gold beam might have been expected to result in a "hole" of reduced light output comparable to the beam size, i.e., dimensions of the order of several centimeters. The substantially larger distance scale of the changes for ${ }^{197} \mathrm{Au}$ was unexpected. The variation is greater in the front section of ZCAL, H1, than in the rear, H2. This is consistent with the observation that the reduction in light output as radiation damage builds-up in ZCAL is greater in $\mathrm{H} 1$ than in $\mathrm{H} 2$. It seems reasonable that at least part of the difference between the two beams should be ascribed to different amounts of radiation damage to the scintillator in ZCAL at the time of the measurements. The ${ }^{28} \mathrm{Si}$ data were obtained with a relatively undamaged calorimeter, while damage was heavy at the time of the present ${ }^{197} \mathrm{Au}$ study.

The dependence of the calorimeter resolution, $\sigma / E_{Z C A L}^{1 / 2}$, on beam position is shown for both projectiles in the upper sections of Fig. 2. Variation with position is weak in each case. Values of $\sigma / E_{Z C A L}^{1 / 2}$ for ${ }^{1} \mathrm{H},{ }^{16} \mathrm{O}$ and various projectile fragments incident on a relatively undamaged ZCAL are comparable to those shown here for ${ }^{28} \mathrm{Si}$ [1]. The much poorer performance of the damaged calorimeter for ${ }^{197} \mathrm{Au}$ is apparent. However, values of $\sigma / E_{Z C A L}^{1 / 2}$ observed during early exposures to ${ }^{197} \mathrm{Au}$ when damage was small were still appreciably larger than expected from the light-ion results. While radiation damage does appear to degrade ZCAL, there appear to be some intrinsic differences between ${ }^{197} \mathrm{Au}$ and ${ }^{28} \mathrm{Si}$. An added complication is that the replacement scintillator may be different from that loaded initially. It has not been possible to perform a definitive experiment to compare ${ }^{197} \mathrm{Au}$ and ${ }^{28} \mathrm{Si}$ directly on an undamaged calorimeter. 


\section{ZCAL Position Signals}

We adopt the same definition of signals for event position characterization as had been used previously[2]. Individual $\mathrm{H} 1$ and $\mathrm{H} 2$ signals are first added to form sums, $H(1)=H_{1}(1)+H_{2}(1), H(2)=H_{1}(2)+H_{2}(2)$, etc. These are then combined to form west, east, up, and down calorimeter half sums:

$$
\begin{aligned}
& W=H(3)+H(4)+H(5)+H(6), \\
& E=H(1)+H(2)+H(7)+H(8), \\
& U=H(1)+H(2)+H(3)+H(4), \\
& D=H(5)+H(6)+H(7)+H(8) .
\end{aligned}
$$

Note that,

$$
E_{Z C A L}=W+E=U+D
$$

Normalized ZCAL position signals are then defined as:

$$
\begin{aligned}
& P_{x}=(W-E) / E_{Z C A L} \\
& P_{y}=(U-D) / E_{Z C A L}
\end{aligned}
$$

$P_{x}$ is plotted as a function of $x$ in Fig. 3 for the data points with $y \sim 0$ and $P_{y}$ as a function of $y$ for the those with $x \sim 0$. Traverses along either axis can be described as exponential growth to saturation characterized by a single parameter, the mean length, $l_{d}$

$$
P_{d}= \pm\left(1-\exp \left(-|d| / l_{d}\right)\right)
$$


where $d$ is $x$ or $y$ and the sign of $P_{d}$ is the same as that of $d$. A least-squares fit, the solid curve in the figure, gives $l_{d}=9.47 \pm 0.08 \mathrm{~cm}$. Separate fits to the $\mathrm{x}$ and $\mathrm{y}$ data give identical $l_{d}$ within errors. Previous results for ${ }^{28} \mathrm{Si}$ are also consistent with Eq. 4 , but with a two-fold longer mean length, $l_{d}=19.6 \pm 0.2 \mathrm{~cm}$. The points for ${ }^{28} \mathrm{Si}$ shown in Fig. 3 are plotted at abscissa values reduced by a factor of $0.48=9.47 / 19.6$ from those measured to correct for this difference.

The behavior in off-axis regions might well be more complex: a simple model of light collection in ZCAL suggested that $l_{x}$ should be a decreasing function of $y$ and, vice versa for $l_{y}[2]$. Because the previous $\mathrm{Si}$ measurements consisted of a single $\mathrm{x}$ traverse at a small $y$, this prediction could not be confirmed. A cross dependence based on the model is incorporated in the POSITION subroutine of the standard ZCAL analysis code and centroid coordinates using that routine are routinely output in the ZCAD banks. The new data for Au which include $\mathrm{y}$ traverses at several $\mathrm{x}$ positions out to $20 \mathrm{~cm}$, provide direct evidence that $l_{y}$ is a function of $\mathrm{x}$. Results for traverses at $x=20.6 \mathrm{~cm}$ (filled points) and $x=12.8 \mathrm{~cm}$ (open points) are compared to the dependence for $x=0 \mathrm{~cm}$ (the dashed curve) in Fig. 4(a). The off-axis data remain consistent with the simple functional form, but $l_{y}$ becomes smaller as $\mathrm{x}$ increases. The variation of $l_{y}(x)$ with $\mathrm{x}$ is shown in Fig. $4(\mathrm{~b})$. The reduction from $l_{y}(0)$ is slow and approximately linear for $\mathrm{x}$ out to $6.7 \mathrm{~cm}$, the dashed line in the figure, but grows rapidly at larger $\mathrm{x}$. The value at $12.8 \mathrm{~cm}$ fall $8 \%$ below the intercept, while that at $20.6 \mathrm{~cm}$ is $33 \%$ lower. The solid curve in Fig. 4(b) represents an arbitrary parameterization which will be incorporated in a revised POSITION subroutine. While the present experiments have mapped a more extensive region of ZCAL than previous studies with ${ }^{28} \mathrm{Si}$, it is clear that behavior in regions beyond $\sim 12$ $\mathrm{cm}$ from the center is subject to considerable uncertainty. This is particularly true since some of data at $x=20.8 \mathrm{~cm}$ required correction because of $\mathrm{ADC}$ saturation by 
the large signals. Fortunately, such large fragment displacements rare in real data.

Coordinates of the mass-weighted centroid of an individual projectile fragment shower can be obtained from the measured $P_{x}$ and $P_{y}$ values by combining the simple exponential form with the arbitrary parameterization for the mean lengths as a function of distance shown in Fig. 4(b),

$$
\begin{aligned}
& x=l_{x}(y) \ln \left(1-P_{x}\right), \\
& y=l_{y}(x) \ln \left(1-P_{y}\right) .
\end{aligned}
$$

These coupled equations are solved by a rapidly-converging iterative procedure starting from starting values $l_{x}(y)=l_{x}(0)$ and $l_{y}(x)=l_{y}(0)$. The algorithm forms the basis of a revised POSITION subroutine for the ZCAL analysis code. The rootmean-square deviation between coordinates generated by the new routine and those input from the calibration runs is $2.3 \mathrm{~mm}$, consistent with the estimated $\sim 2$-mm uncertainty on the physical position determinations.

Results generated by the new POSITION routine for a typical gold run, run 17191, one of the $2 \mathrm{~K}$ p-bar series, are presented in Figs. 5 and 6: individual $x$ and $y$ distributions for clean BEAM, INT, and SPEC1 triggers in the former, two-parameter profiles for the same triggers in the latter. Distribution widths grow as events become more central and profiles shift from the vertical ellipse characteristic of the beam spot to essentially circular for SPEC1 events. Had the old POSITION routine been used in this analysis, all distances would have been a factor of $\sim 2$ larger than those shown, a direct consequence of the longer mean length for ${ }^{28} \mathrm{Si}$.

\section{CONCLUSIONS}

The present series of measurements provides evidence that ZCAL's response to a Au beam is drastically differentnow than it was to a Si beam earlier. It seems probable 
that at least part of the difference should be ascribed to a reduction of light output due to radiation damage: the scintillator in ZCAL was relatively undamaged at the time of the $\mathrm{Si}$ studies, but is heavily damaged now. It is observed experimentally that both $E_{Z C A L}$ and the $H_{1} / H_{2}$ ratio decrease with increasing damage for centrally incident beams of either Si or Au. The "standard" two point linear calibration of $E_{Z C A L}$ using the beam energy and pedestals may be adequate for some applications. It is simple to implement on a run-by-run basis, but is at best an approximation which ignores details of the radiation damage process in ZCAL as well as nonlinearities of response to beam particles of high charge.

Reduced light output may not be the only effect of radiation damage: any dependence on signal size should be removed by the normalization in calculating $P_{x}$ and $P_{y}$, yet the $\mathrm{Si}$ and $\mathrm{Au}$ mean lengths differ by a factor of two. This suggests that light transmission might also be reduced in the damaged regions. However, on the basis of only two calibration experiments other possibilities cannot be ruled out: (1), optical transmission of the initial batch of scintillator in ZCAL was greater than that loaded in the summer of 1992; (2), the scale change is due to some intrinsic difference between $\mathrm{Si}$ and Au stopping in ZCAL; or (3), some combination of these and radiation damage. As a consequence, position determinations are subject to considerable uncertainty, except for data acquired near the time of a calibration. A similar "moving" experiment with the Au beam after ZCAL has been reloaded with fresh scintillator and another after appreciable damage has accumulated will be important to resolve the various possibilities.

\section{ACKNOWLEDGMENTS}

This research was performed at Brookhaven National Laboratory under contract DE-AC02-76CH00016 with the U.S. Department of Energy. 


\section{REFERENCES}

[1] D. Beavis et al., Nucl. Instr. and Meth. A281, 367 (1989).

[2] J.B. Cumming et al., E802 internal report, E-802-MEM-40 (1989).

[3] T. Abbott et al., Phys. Rev. Lett. 70, 1393 (1993).

[4] J.C. Dunlop and M.D. Baker, E866 internal report, E-866-MEM-19 (1995).

\section{DISCLAIMER}

This report was prepared as an account of work sponsored by an agency of the United States Government. Neither the United States Government nor any agency thereof, nor any of their employees, makes any warranty, express or implied, or assumes any legal liability or responsibility for the accuracy, completeness, or usefulness of any information, apparatus, product, or process disclosed, or represents that its use would not infringe privately owned rights. Reference herein to any specific commercial product; process, or service by trade name, trademark, manufacturer, or otherwise does not necessarily constitute or imply its endorsement, recommendation, or favoring by the United States Government or any agency thereof. The views and opinions of authors expressed herein do not necessarily state or reflect those of the United States Government or any agency thereof. 


\section{FIGURES}

FIG. 1. Some general information on the Zero Degree Calorimeter, ZCAL, of E802/ES59/E866.

FIG. 2. (a); ZCAI response to a 2088-GeV kinetic energy ${ }^{197} \mathrm{Au}$ beam. The total energy signal, $E_{Z C A L}$ and the outputs from the separate sections, $\mathrm{H} 1$ and $\mathrm{H} 2$, as well as the resolution constant, $\sigma / E^{1 / 2}$, are shown as a function of beam distance from the calorimeter center. (b); Similar data for an incident $381-\mathrm{GeV}^{28} \mathrm{Si}$ beam.

FIG. 3. Dependence of the $P_{x}$ and $P_{y}$ signals from ZCAL on the beam position relative to the calorimeter center. Data for $\mathrm{x}$ and $\mathrm{y}$ traverses with a Au beam and for an $\mathrm{x}$ traverse with Si are indicated by different symbols. Abscissas of the Si data have been scaled to reflect the different mean length for that ion, see text. The solid curve is the best fit to an exponential growth function.

FIG. 4. (a); Exponential dependence of $1-P_{y}$ on $y$ for selected values of $x$ as indicated. (b); Dependence of the derived $y$ mean length on $x$. The dashed line is a linear fit to the points for $x<\tau$. The solid curve is an arbitrary function employed in position determinations, see text.

FIG. 5. Fragment centroid $\mathrm{x}$ and $\mathrm{y}$ distributions for BEAM, INT, and SPECI triggers for a typical $2 \mathrm{~K}$ p-bar run. A Gaussian fit is shown for each histogram. 
FIG. 6. Fragment centroid profiles for BEAM, INT, and SPEC1 triggers for a typical $2 \mathrm{~K}$ p-bar run. 
- ZCAL is divided into two sections, $\mathrm{H} 1$ and $\mathrm{H} 2$
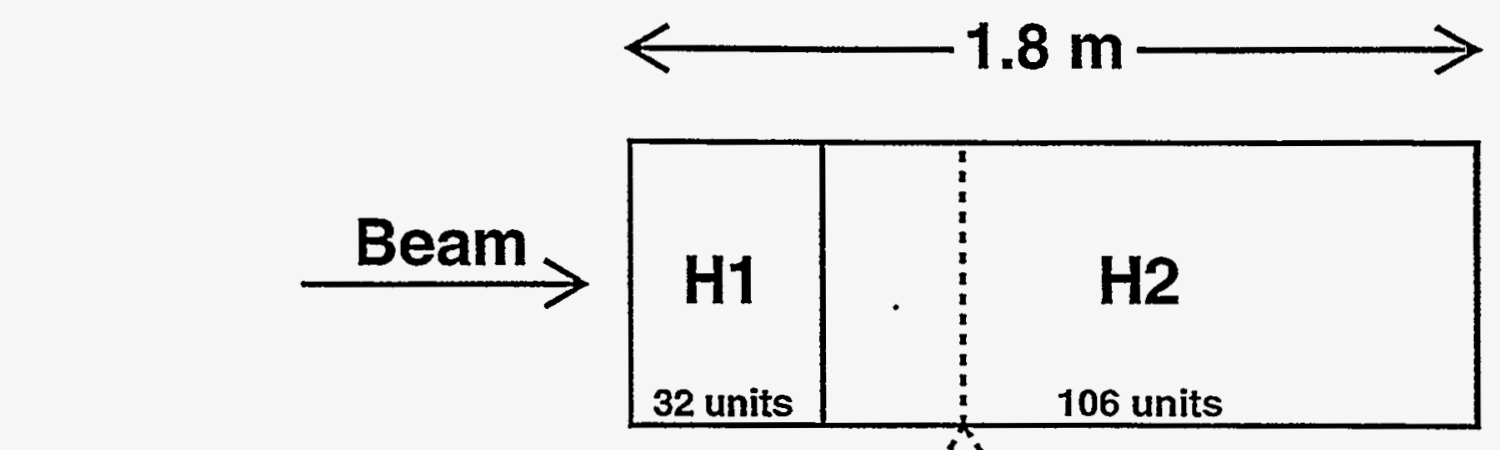

- Built from stacking units

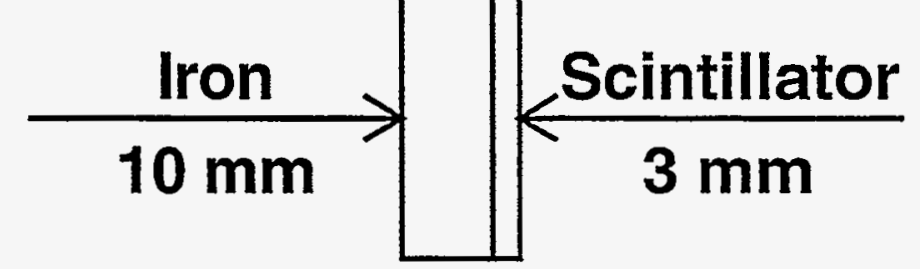

- Readout by Wave-Length Shifters (Cross Hatched) eight each for $\mathrm{H} 1$ and $\mathrm{H} 2$, numbered, as seen by the beam
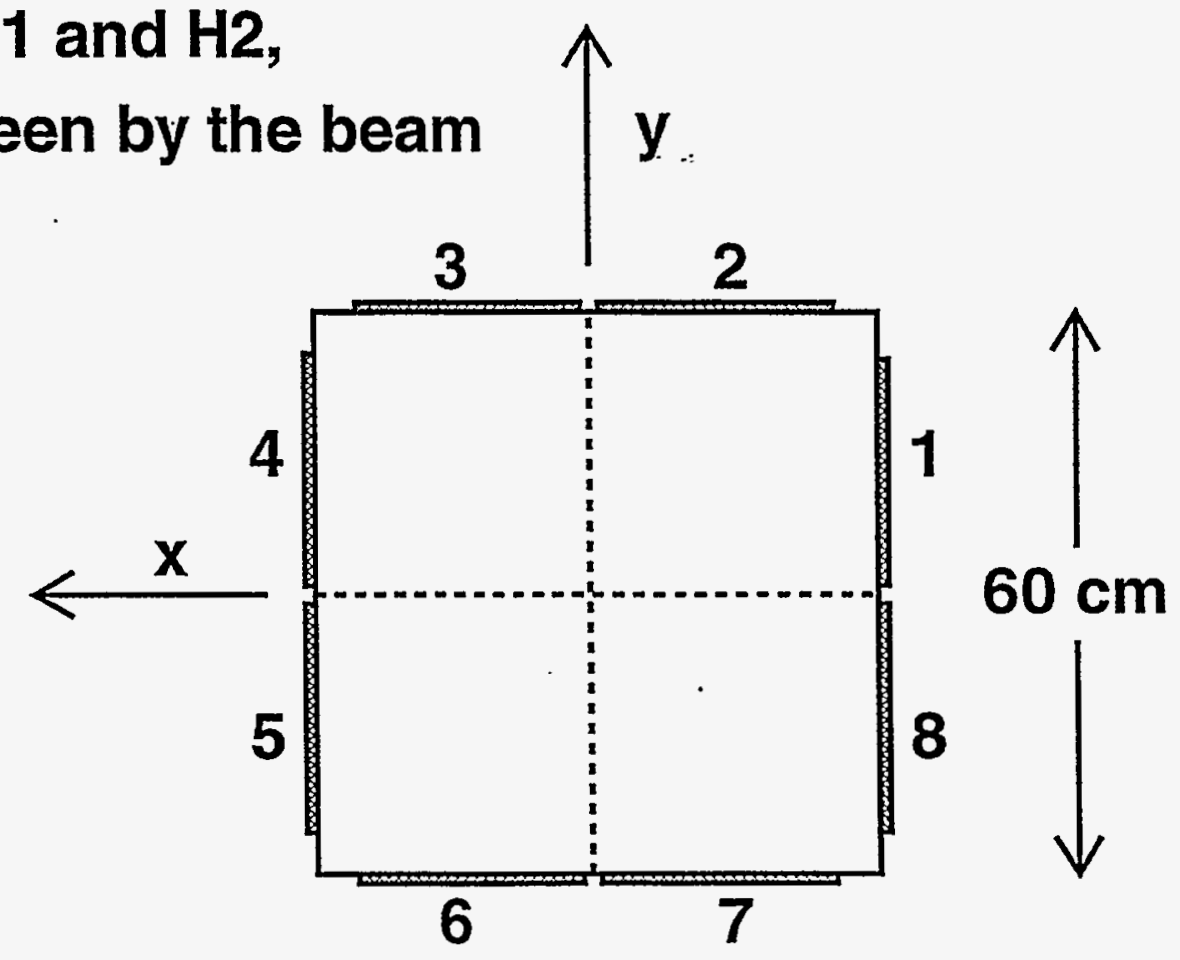

Figure 1 


\section{(a) ${ }^{197} \mathrm{Au}$}

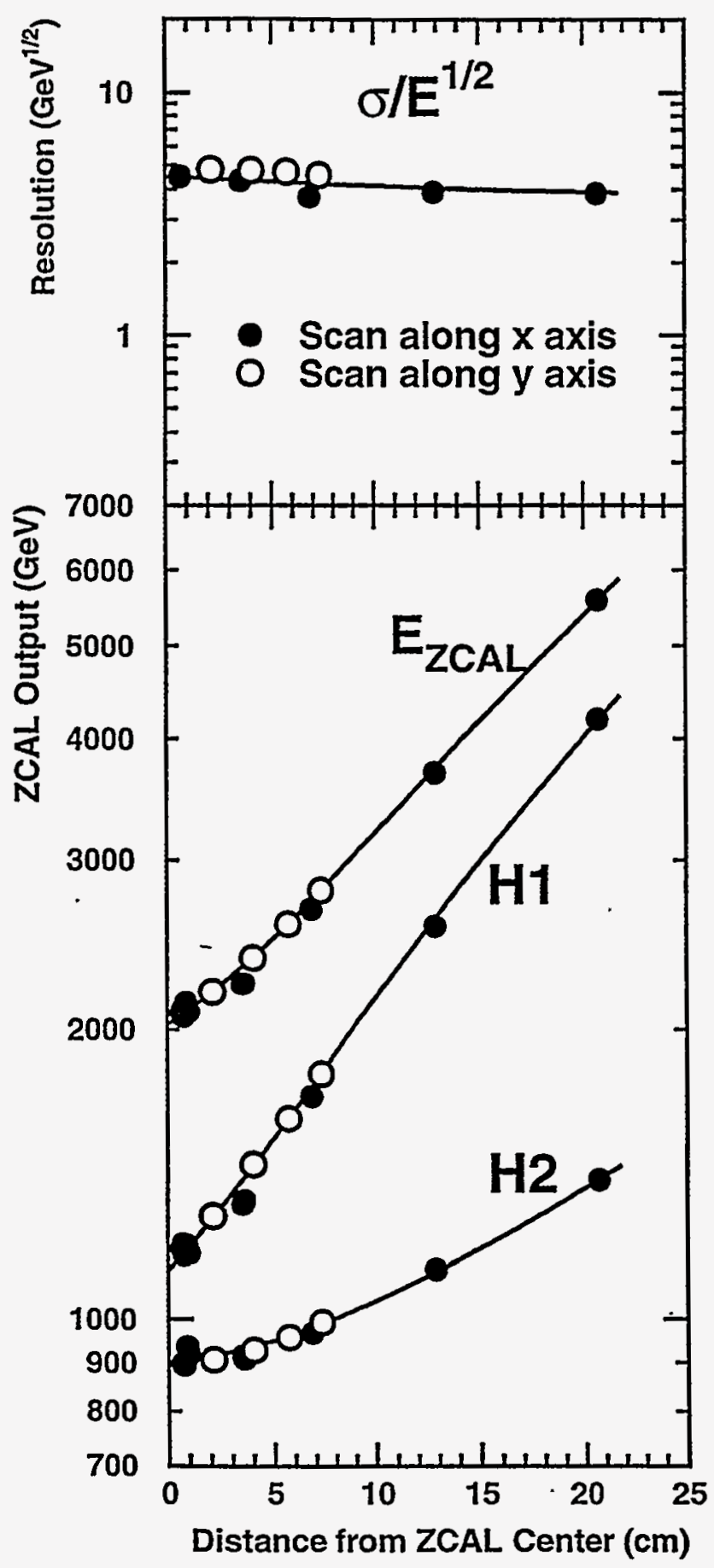

(b) ${ }^{28} \mathrm{Si}$

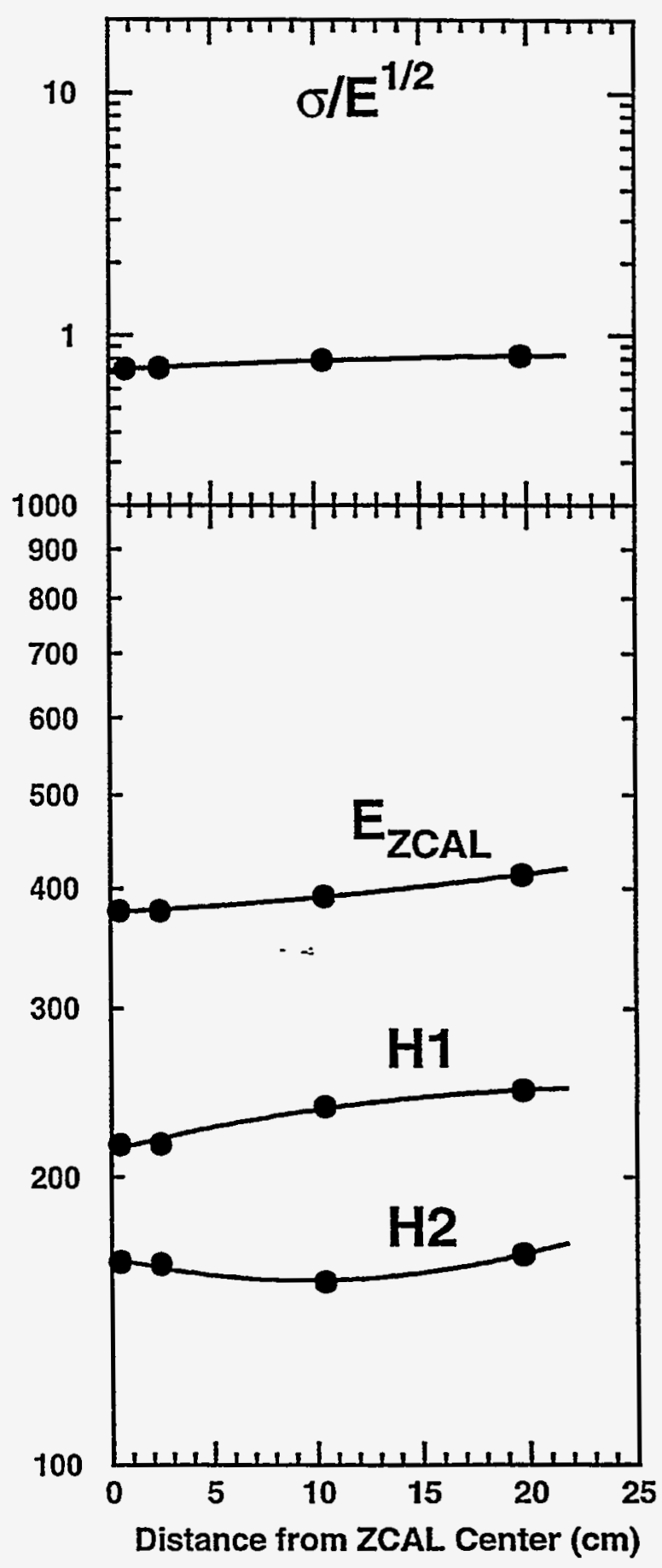

Figure 2 


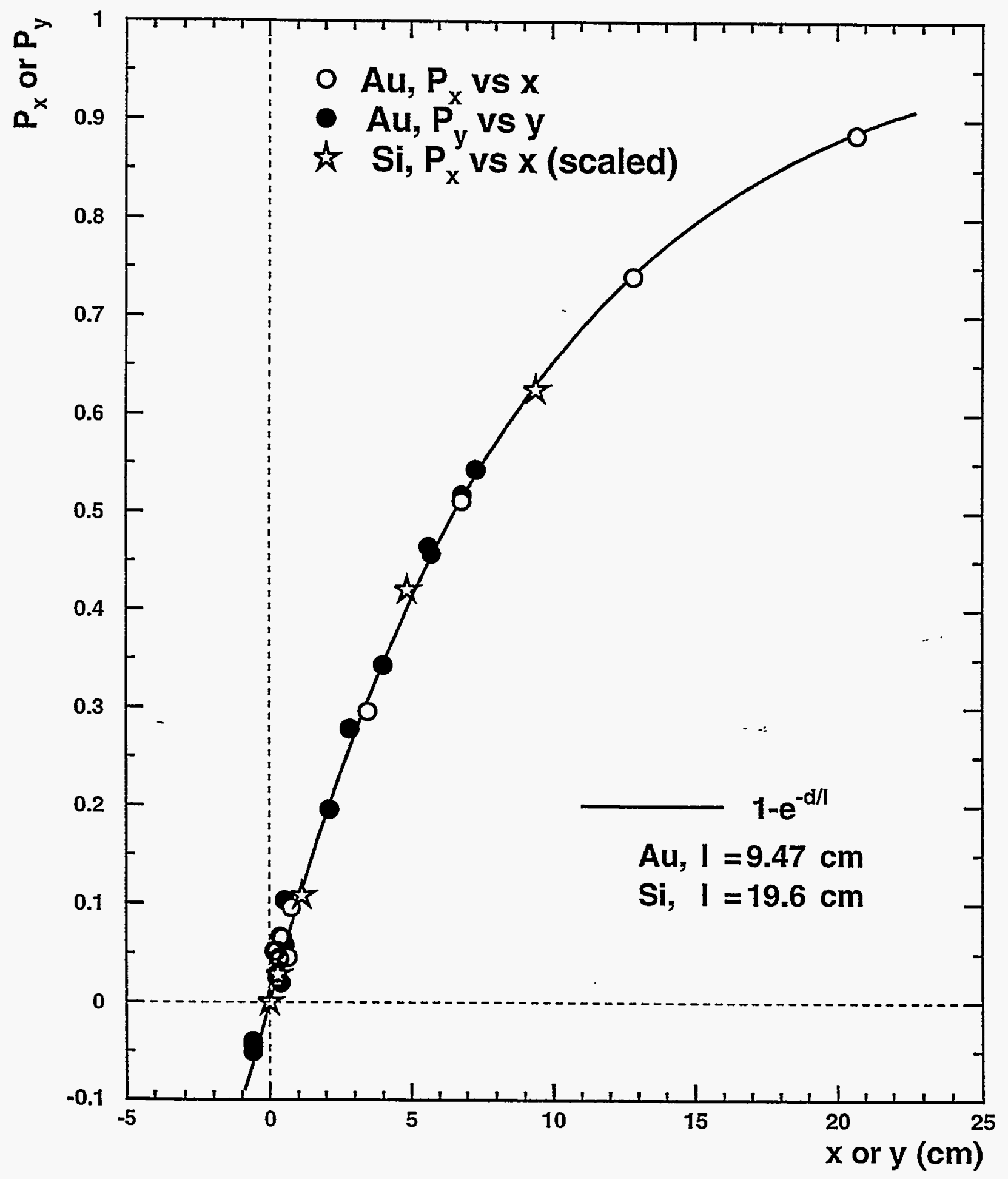



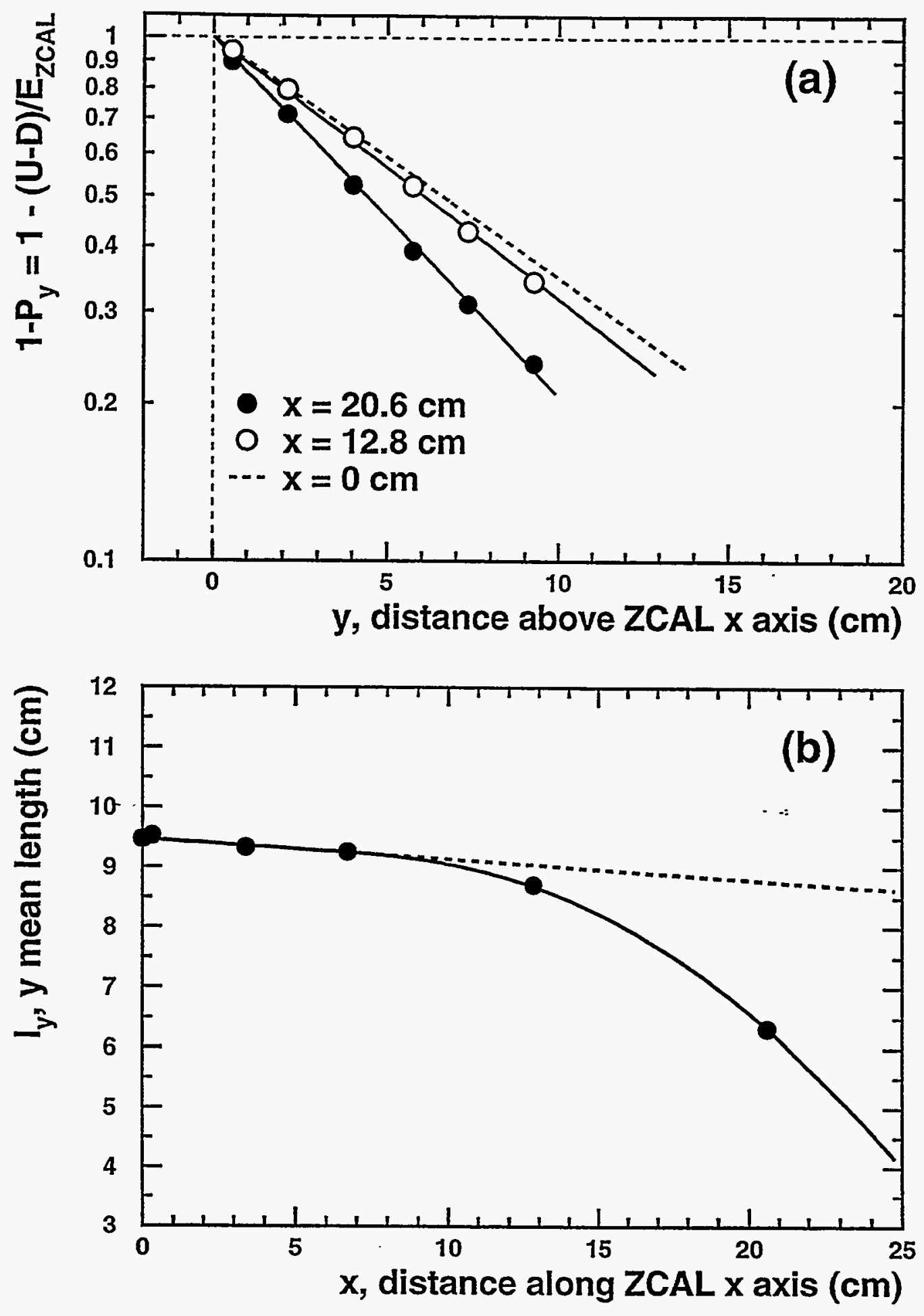

Figure 4 

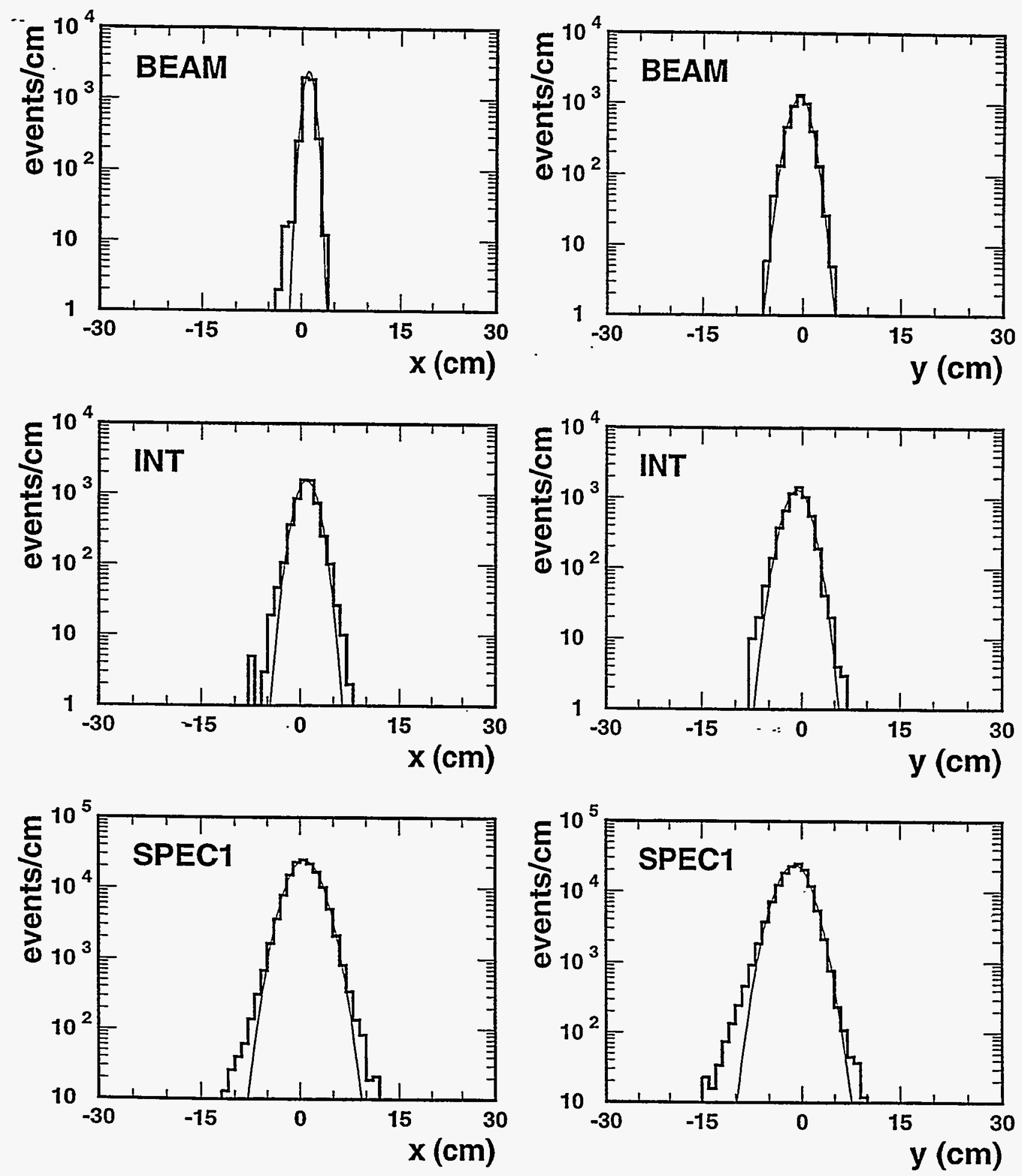

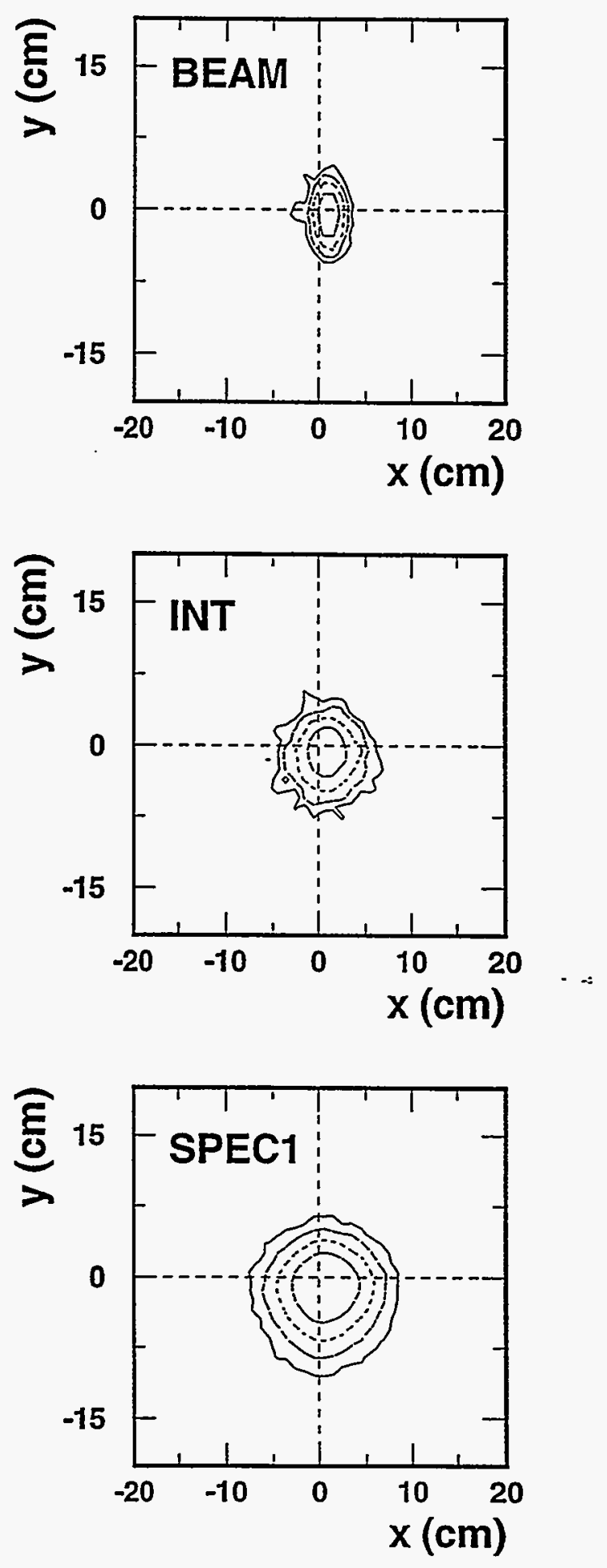

Figure 6 